\title{
Yağışın Alansal Dağılımının Haritalandırılmasında Enterpolasyon Yöntemlerinin Karşılaştırılması: Akdeniz Bölgesi Örneği
}

\author{
Ahmet ILKER ${ }^{1}$

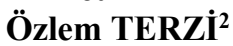 \\ Erhan ŞENER ${ }^{3}$
}

\section{ÖZ}

Çalışmada, Coğrafi Bilgi Sistemleri (CBS) ile Akdeniz Bölgesi'nde yağışın alansal dağılım haritaları oluşturulmuştur. Ters Mesafe Ağırlıklı, Kriging ve Spline enterpolasyon yöntemleri kullanılmıştır. Haritaların doğruluk analizi, determinasyon katsayısı $\left(\mathrm{R}^{2}\right)$ ve karekök ortalama hata değerlerine göre yapılmıştır. Yapılan analizler sonucunda, genel olarak IDW enterpolasyon yönteminin uygun sonuçlar verdiği belirlenmiştir. Ayrıca, Kriging yöntemi de bazı istasyonlarda IDW yönteminden daha yüksek $\mathrm{R}^{2}$ değerleri vermiştir. Akdeniz Bölgesi'nde yağışın alansal dağılımında IDW enterpolasyon yönteminin kullanılabilir olduğu tespit edilmiştir.

Anahtar Kelimeler: Akdeniz Bölgesi, yağış, CBS, IDW, kriging, spline.

\section{ABSTRACT \\ Comparing of Interpolation Methods in Mapping Spatial Distributions of Rainfall: Case Study of Mediterranean Region}

In the study, spatial distribution maps of rainfall in the Mediterranean Region have been prepared with Geographic Information Systems (GIS). Inverse Distance Weighted (IDW), Kriging and Spline interpolation methods have been used. The accuracy analysis of maps has been made regarding the determination coefficient $\left(\mathrm{R}^{2}\right)$ and the root mean square error values. Examining results of the analysis, it has been determined that IDW interpolation method usually provides appropriate results. Moreover, Kriging interpolation method gives higher

Not: Bu yazı

- Yayın Kurulu'na 11.08.2017 günü ulaşmıştır. 17.04.2018 günü yayımlanmak üzere kabul edilmiştir.

- 31 Temmuz 2019 gününe kadar tartışmaya açıktır.

- https://dx.doi.org/10.18400/tekderg.334186

1 Çankırı Karatekin Üniversitesi, İnşaat Mühendisliği Bölümü, Çankırı - ahmetilker@karatekin.edu.tr https://orcid.org/0000-0002-6276-7309

2 Süleyman Demirel Üniversitesi, İnşaat Mühendisliği Bölümü, Isparta - ozlemterzi@sdu.edu.tr https://orcid.org/0000-0001-6429-5176

2 Süleyman Demirel Üniversitesi, Uzaktan Algılama Merkezi, Isparta - erhansener@sdu.edu.tr https://orcid.org/0000-0001-6263-8366 
$\mathrm{R}^{2}$ values than IDW method in various stations. It has been found out that IDW interpolation method is applicable in spatial distribution of rainfall in the Mediterranean Region.

Keywords: Mediterranean Region, rainfall, GIS, IDW, kriging, spline.

\section{GíRiș}

Günümüzde hidroloji, tarım, ekoloji, orman yönetimi, meteoroloji vb. birçok farklı disiplinde yürütülen çalışmalarda değişik iklim parametreleri kullanılmaktadır. Doğru iklimsel veriler ancak noktasal olarak, meteoroloji gözlem istasyonlarının bulunduğu yerlerden elde edilebilmektedir. Oysaki birçok çalışmada alansal dağılım özelliği gösteren iklim parametrelerine ihtiyaç duyulmaktadır. $\mathrm{Bu}$ yüzden günümüzde, noktasal gözlem değerlerinden faydalanarak alansal dağılım özelliği gösteren iklim veri katmanlarının üretilmesine yönelik ihtiyaç ve ilgi giderek artış göstermektedir. Konumsal veri tabanı uygulamalarının vazgeçilmez bir parçası olan coğrafi bilgi sistemlerinin (CBS) iklim çalışmalarında kullanılması kaçınılmaz bir hal almıştır[1]. Noktasal meteorolojik veri olan yağışın alansal dağılımını gerçekleştirmek için CBS'nin kullanıldığı, güvenilir sonuçlar veren birçok çalışma mevcuttur.

Bu çalışmada Akdeniz Bölgesi için farklı enterpolasyon yöntemleri ile elde edilen yağış alansal dağılımları karşılaştırılmıştır. Çalışmada kullanılan meteoroloji istasyonlarından bazıları doğruluk analizi için ayrılmıştır. Bu istasyonların ölçülen değerleri ile enterpolasyon yöntemlerinden elde edilen değerler klyaslanarak en uygun enterpolasyon yöntemi belirlenmeye çalışılmıştır.

\section{MATERYAL VE YÖNTEM}

\section{1. Çalışma Bölgesi ve Veriler}

Akdeniz Bölgesi'nin genişliği 120 - $180 \mathrm{~km}$ arasında değişen bir şerit halinde, batıda Köyceğiz dolaylarından başlayarak, doğuda Hatay ilinin bitim noktası olan Basit Burnu yakınına kadar sokulur.

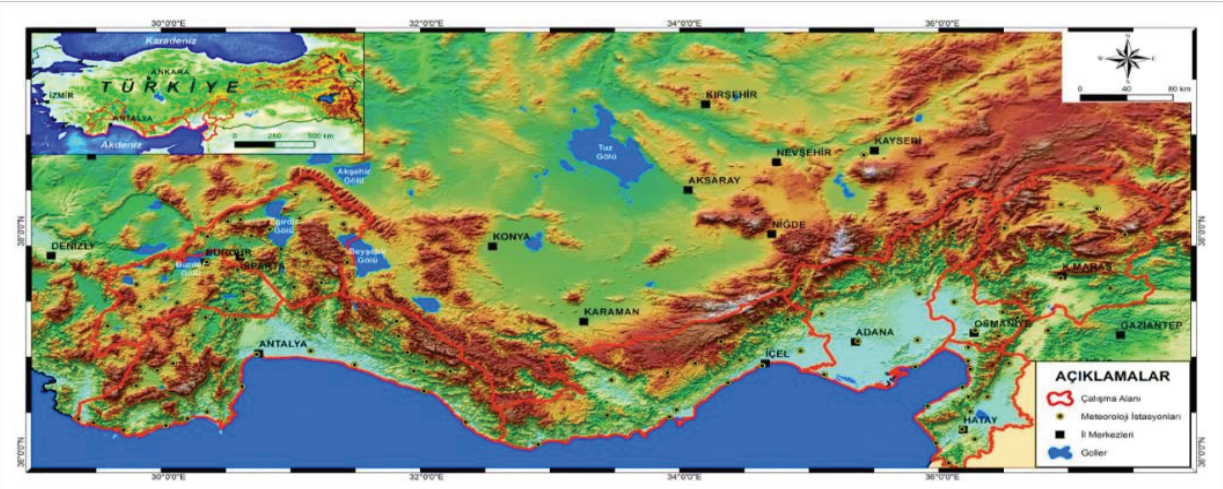

Şekil 1- Çalışma alanının yerbulduru haritası 
Yaklaşık 120.000 km²'lik yüzölçümüyle Türkiye'nin toplam yüzölçümünün yaklaşık \%15'ini oluşturur (Şekil 1). Yıllık sıcaklık ortalaması $18^{\circ} \mathrm{C}^{\prime}$ dir. Kıyıda yıllık yağış miktarının 1000 mm'yi bulduğu yerler vardır. Akdeniz kıyıları kış mevsiminin en 1lık geçtiği bölgemizdir.

Çalışmada, Devlet Meteoroloji İşleri Genel Müdürlüğü’ne ait Akdeniz Bölgesi'nde bulunan 99 adet meteoroloji istasyonunun uzun yıllar aylık toplam yağış ortalaması verileri (19752009) kullanılmıştır.

\subsection{Enterpolasyon Yöntemleri}

Coğrafi bilgi sistemi (CBS) temelde bir bilgi sistemidir. Bilgi sistemleri genel olarak "bilgi elde etmek için, verileri önceden belirlenmemiş biçimlerde anlık yöntemlerle kullanılmak üzere saklayan bir sistem" biçiminde tanımlanmaktadır. CBS ortamında enterpolasyon ile raster yüzey oluşturmanın çeşitli yolları vardır. Bu çalışmada IDW (Inverse Distance Weighted), Spline ve Kriging enterpolasyon yöntemleri, değerleri bilinmeyen noktaları doğru bir şekilde kestirmek için kullanılmıştır. Modellenen veri türüne göre seçilen enterpolasyon yöntemleri daha doğru modeller ortaya koyar. Bunun yanında fazla sayıda ölçüm yapılması ve noktaların olabildiğince üniform dağılımı da güvenilir sonuçların ortaya çıkmasını sağlamaktadır [2].

Ters Mesafe Ağırlıklı Enterpolasyon Yöntemi (Inverse Distance Weighted - IDW) örneklem nokta verilerinden enterpolasyonla grid üretmede çoğunlukla tercih edilen bir yöntemdir. IDW enterpolasyon tekniği enterpole edilecek yüzeyde yakındaki noktaların uzaktaki noktalarda daha fazla ağırlığa sahip olması esasına dayandırılmıştır. Bu teknik enterpole edilecek noktadan uzaklaştıkça ağırlığı da azaltan ve örneklem noktalarının ağırlıklı ortalamasına göre bir yüzey enterpolasyonu yapar. Kriging enterpolasyon yöntemi konumsal tahmin için kullanılan geoistatistiksel esaslı bir yöntemdir. $\mathrm{Bu}$ yöntem, matematiksel jeodezide kollokasyon olarak bilinen en iyi lineer yansız tahminci ya da en iyi lineer yansız hesaplayıcı olarak tanımlanır. Kriging yöntemi birçok alanda kullanılabilirliği ve popülaritesi kanıtlanmış bir enterpolasyon yöntemidir [3]. Spline enterpolasyon yöntemi ise giriş değerlerinden (değeri bilinen noktalar) minimum eğrilik yüzeyi geçirerek enterpolasyon işlemini gerçekleştirmektedir. Bu yöntem yükseklik, su derinliği haritası ve hava kirliliği grafiklerinde tercih edilir. Bu fonksiyon kısa yatay mesafelerde büyük değişimlerin olduğu veriler için uygun değildir [2].

\section{BULGULAR VE TARTIŞMA}

Bu çalışmada, Akdeniz Bölgesi için farklı enterpolasyon teknikleri ile yağışın alansal dağılım haritaları oluşturulmuştur. Bunun için, bölgede bulunan 99 adet meteoroloji istasyonunun uzun yıllar aylık toplam yağış ortalaması verileri kullanılmıştır. Yılın her ayı için üç farklı enterpolasyon tekniği ile seçilen 80 adet istasyonun verileri kullanılarak yağış dağılım haritaları oluşturulmuştur. Doğruluk analizi için kalan 19 adet istasyon verileri kullanılarak Akdeniz Bölgesi için yağış dağılımında en uygun enterpolasyon yöntemi belirlenmeye çalışılmıştır. Söz konusu olan 19 adet doğruluk analizi test istasyonlarının konumları ve ölçüm değerleri ve veri gurubundaki yerleri belirlenirken, Doğru vd. [4]'nde belirtilen hususlar göz önünde bulundurulmuştur. 


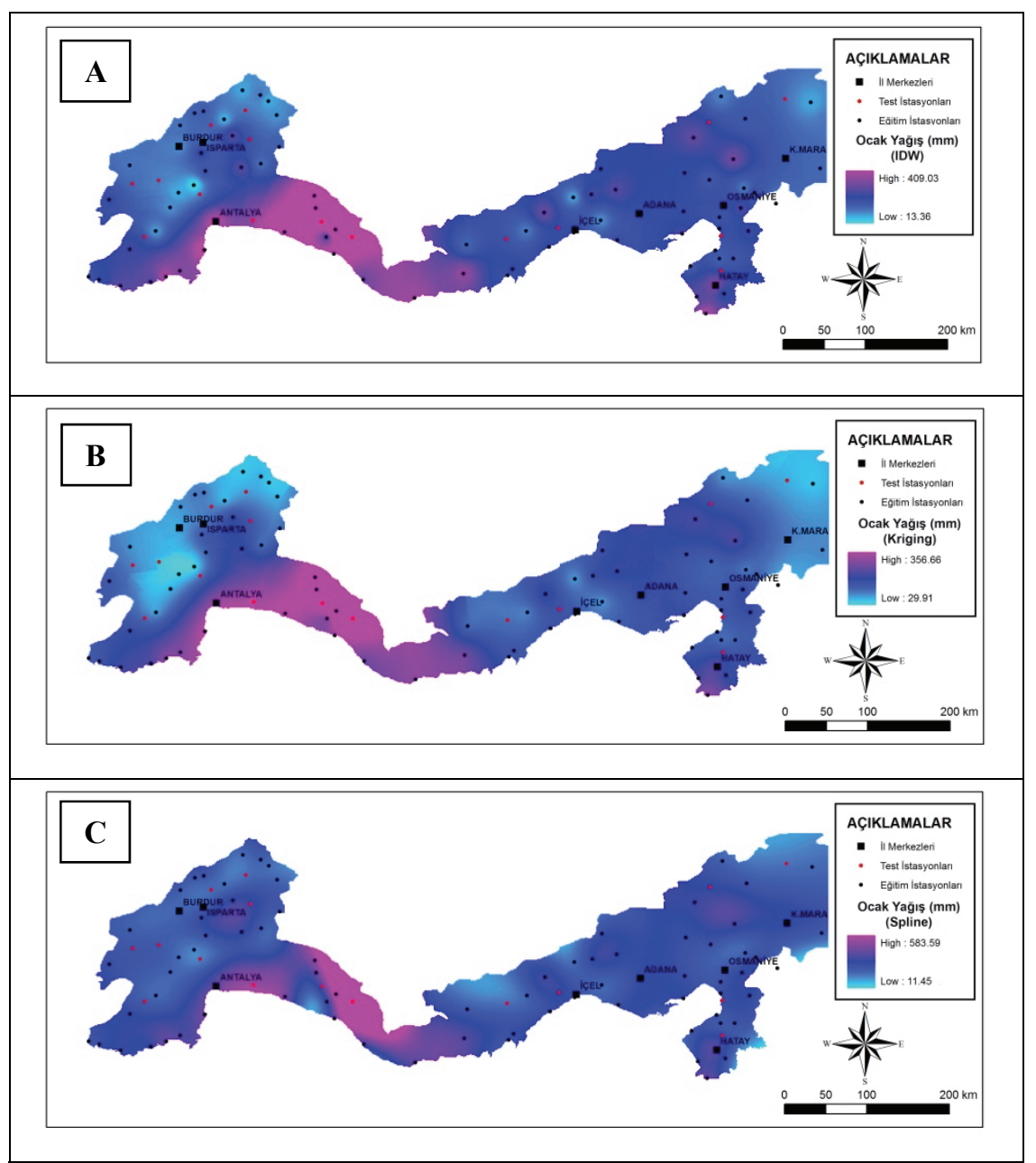

Şekil 2- Ocak ayı ortalama yă̆ış dă̆llım haritaları (A-IDW, B-Kriging, C-Spline)

ArcGIS yazılımı ortamında Mekansal Analiz (Spatial Analyst) aracı kullanılarak, Ters Mesafe Ağırlıklı (Inverse Distance Weighted - IDW), Ordinary Kriging ve Spline enterpolasyon yöntemleriyle her ay için yağış dağılım haritaları oluşturulmuştur (Şekil 2). DMİ tarafindan ölçülen yağış değerlerinin minimum ve maksimum değerleri ile IDW, Kriging ve Spline enterpolasyon yöntemleri kullanılarak elde edilen yağış dağılım haritalarından okunan minimum ve maksimum yağış değerleri incelendiğinde, çalışma bölgesinin en çok kış aylarında (Aralık, Ocak, Şubat) yağış aldığı tespit edilmiştir. Bu değerler mevsimlere göre incelendiğinde ise, kış mevsiminden sonra sırasıyla sonbahar, ilkbahar ve yaz mevsimlerinde en çok yağ 1 ş aldığ1 görülmüştür. Bölge, minimum yağış1 A ğustos ayında $(0.1 \mathrm{~mm})$, maksimum yağışı $(409.1 \mathrm{~mm})$ Ocak ayında almıştır. Özellikle Mayıs, Haziran, Ekim, Kasım ile nispeten Mart ve Nisan aylarında üç enterpolasyon 
yöntemine göre yağışın minimum ve maksimum gözlendiği alanlar birbirine çok yakın sonuçlar vermiştir. Diğer aylarda ise enterpolayon sonuçlarının nispeten birbirlerinden çok daha farklı sonuçlar verdiği gözlenmiştir. Örneğin Ocak ayı yağış dağılım haritaları incelendiğinde üç enterpolasyon yöntemine göre maksimum yağışın Antalya çevresinde olduğu görülmüştür. Minimum yağışın ise IDW yöntemine göre Burdur, Kriging yöntemine göre Burdur, Isparta ve Kahramanmaraş, Spline yöntemine göre ise İçel çevresinde olduğu görülmüştür.

Çizelge 1 - Doğruluk analizi istasyonları için hesaplanan R2 ve KOH değerleri

\begin{tabular}{ccccccc}
\hline \multirow{2}{*}{ Istasyon adı } & \multicolumn{2}{c}{ IDW } & \multicolumn{2}{c}{ Kriging } & \multicolumn{2}{c}{ Spline } \\
\cline { 2 - 7 } & $\mathrm{R}^{2}$ & $\mathrm{KOH}(\mathrm{mm})$ & $\mathrm{R}^{2}$ & $\mathrm{KOH}(\mathrm{mm})$ & $\mathrm{R}^{2}$ & KOH $(\mathrm{mm})$ \\
\hline Gelendost & 0.73 & 12.56 & 0.50 & 16.95 & 0.39 & 18.77 \\
Atabey & 0.57 & 12.48 & 0.55 & 12.68 & 0.80 & 8.41 \\
Aksu & 0.85 & 15.94 & 0.76 & 19.78 & 0.73 & 20.95 \\
Kemer-Sertaç & 0.79 & 5.83 & 0.75 & 6.32 & 0.25 & 10.99 \\
Tefenni & 0.92 & 5.27 & 0.93 & 5.24 & 0.69 & 10.66 \\
Dă̆ & 0.30 & 39.60 & 0.69 & 26.48 & 0.27 & 40.41 \\
Elmalı & 0.95 & 5.38 & 0.55 & 16.43 & 0.82 & 10.50 \\
Serik & 0.94 & 20.24 & 0.94 & 19.62 & 0.89 & 26.75 \\
Güzelsu-Antalya & 0.87 & 40.66 & 0.80 & 50.03 & 0.87 & 40.52 \\
Köprülü & 0.85 & 38.37 & 0.88 & 34.63 & 0.67 & 57.14 \\
Kırobası & 0.42 & 21.53 & 0.46 & 20.78 & 0.39 & 22.20 \\
Kuzucubelen & 0.56 & 24.46 & 0.46 & 27.03 & 0.38 & 29.08 \\
Adana & 0.95 & 7.85 & 0.94 & 8.95 & 0.58 & 23.80 \\
Serinyol & 0.93 & 12.87 & 0.94 & 11.73 & 0.94 & 11.86 \\
Payas-Yakacık & 0.52 & 15.36 & 0.40 & 17.06 & 0.36 & 17.65 \\
Osmaniye & 0.96 & 6.99 & 0.97 & 6.01 & 0.91 & 11.06 \\
Kahramanmaraş & 0.82 & 20.34 & 0.79 & 21.77 & 0.80 & 21.38 \\
Saimbeyli & 0.75 & 21.65 & 0.69 & 23.75 & 0.65 & 25.54 \\
Afşin & 0.74 & 10.61 & 0.44 & 15.43 & 0.32 & 16.97 \\
\hline
\end{tabular}

Ortalama yağışın 12 aylık periyot boyunca alansal dağılımında en uygun enterpolasyon yöntemini belirlemek için, doğruluk analizinde kullanılan istasyonlardan ölçülen yağış değerleri ile enterpolasyon yöntemlerinden elde edilen yağış değerleri determinasyon katsayısı $\left(\mathrm{R}^{2}\right)$ ve karekök ortalama hata $(\mathrm{KOH})$ değerlerine göre karşılaştırılmıştır (Çizelge 1). Buna göre 19 adet analiz istasyonundan 10 adet istasyonda IDW enterpolasyon yönteminde yüksek $\mathrm{R}^{2}$ ve en düşük $\mathrm{KOH}$ değerleri elde edilmiştir. Bu istasyonlar içerisinde 
en yüksek $\mathrm{R}^{2}(0.96)$ ve en düşük $\mathrm{KOH}(6.99 \mathrm{~mm})$ değerleri Osmaniye istasyonunda hesaplanmıştır. Analiz istasyonlarına bakıldığında Dağ, Kırobası, Payas-Yakacık, Kuzucubelen ve Atabey istasyonlarında diğer istasyonlara göre nispeten daha düşük $\mathrm{R}^{2}$ değerleri elde edilmiştir. Kriging enterpolasyon yönteminde ise sırasıyla Osmaniye, Adana, Serinyol, Serik ve Tefenni istasyonlarında diğer istasyonlara göre daha yüksek $\mathrm{R}^{2}$ değerleri bulunmuştur. Spline enterpolasyon yöntemi ile Serinyol ve Osmaniye istasyonlarında en yüksek $\mathrm{R}^{2}$ değerleri elde edilmiştir. Bütün istasyonlar için kullanılan yöntemler incelendiğinde, genel olarak IDW yöntemi en başarılı yöntem olarak belirlenmekle birlikte en yüksek $\mathrm{R}^{2}$ değerini Kriging yöntemi 0.97 ile Osmaniye istasyonunda vermiştir.

Kırobası, Kuzucubelen ve Payas-Yakacık istasyonlarının $\mathrm{R}^{2}$ değerlerinin, bütün enterpolasyon yöntemlerinde düşük olduğu tespit edilmiştir. $\mathrm{Bu}$ durumun sebebi araştırıldığında, üç istasyonun da çevrelerindeki meteoroloji istasyonlarından yağış rejimleri ve aylık yağış değerleri olarak farklılıklar gösterdiği tespit edilmiştir.

\section{SONUÇLAR}

Çalışmada, DMİ Genel Müdürlüğü'nden temin edilen yağış verileri ile CBS ortamında IDW, Kriging, Spline enterpolasyon yöntemleri kullanılarak ortalama aylık yağış dağılım haritaları oluşturulmuştur. Söz konusu haritaların $\mathrm{R}^{2}$ ve $\mathrm{KOH}$ kriterlerine göre doğruluk analizini yapmak için 19 adet meteoroloji istasyonu test istasyonu olarak kullanılmıştır. Test istasyonlarının doğruluk analizine göre Akdeniz Bölgesi için yağışın alansal dağılımının haritalanmasında en uygun yöntemin IDW enterpolasyon yöntemi olduğu belirlenmiştir. Ayrıca Spline enterpolasyon yönteminin yağışın alansal dağılımının haritalanmasında uygun olmadığı tespit edilmiştir. Yağışın iklim, bitki örtüsü ve topoğrafya gibi faktörler ile doğrudan ilişkili olduğu düşünüldüğünde Akdeniz Bölgesi'ne benzer özellikler gösteren ve yağış rejimi benzer olan bölgelerde yağışın alansal dağılımının haritalanmasında IDW enterpolasyon yönteminin uygulanabilir olduğu görülmüştür.

Çalışmada kullanılan tüm enterpolasyon yöntemlerinde, Kırobası, Kuzucubelen ve PayasYakacık istasyonlarında başarılı sonuçlar elde edilememesinin sebebi olarak sözkonusu istasyonların yakınlarındaki istasyonlardan yağış miktarları bakımından farklılık göstermesi düşünülmektedir.

Sonuç olarak, hidroloji çalışmalarında önemli bir parametre olan yağışın belirli bir alan üzerindeki dağılımı hakkında bilgi sahibi olabilmek, meteoroloji istasyonunun bulunmadığı noktalarda yağış miktarını tahmin edebilmek, istasyonların arızalanması veya veri kaybı gibi durumlarda tahmin yapabilmek için IDW enterpolasyon yönteminin kullanılabilir olduğu belirlenmiştir.

\section{Teşekkür}

“Akdeniz Bölgesi'nde Yağışın Alansal Dağılımı” konuluve 2192-YL-10 no.lu proje kapsamında bu çalışmayımaddi olarak destekleyen SDÜ Araştırma Projeleri Koordinasyon Birimi'ne teşekkür ederiz. 


\section{Kaynaklar}

[1] Güler, M., Kara, T., Alansal Dağılım Özelliği Gösteren İklim Parametrelerinin Coğrafi Bilgi Sistemleri İle Belirlenmesi Ve Kullanım Alanları; Genel Bir Bakış, OMÜ Ziraat Fakültesi Dergisi, 22(3), 322-328, 2007.

[2] Şen, A., Elektrik Alan Şiddetlerinin Ölçümü ve Coğrafi Bilgi Sistemi Ortamında Yapay Sinir Ağları İle Analizi, Yüksek Lisans Tezi, Yıldız Teknik Üniversitesi Fen Bilimleri Enstitüsü, 2007.

[3] Köroğlu, S., Farklı EnterpolasyonYöntemlerinin Hacim Hesabına Etkisinin Araştırılması, Yüksek Lisans Tezi, İstanbul Teknik Üniversitesi Fen Bilimleri Enstitüsü, 2006.

[4] Doğru, A. Ö., Keskin, M., Özdoğdu, K., İliev, N., Uluğtekin, N. N., Balçık, Bektaş, F., Göksel, Ç., Sözen, S., Meteorolojik Verilerin Değerlendirilmesi ve Sunulması İçin Enterpolasyon Yöntemlerinin Karşılaştırılması, TMMOB Coğrafi Bilgi Sistemleri Kongresi, Antalya, 2011. 
